Article

\title{
Titanium and Vanadium Catalysts with 2-Hydroxyphenyloxazoline and Oxazine Ligands for Ethylene-Norbornene (co)Polymerization
}

 \\ Karel Doležal 2,3 (iD \\ 1 Faculty of Chemistry, University of Opole, Oleska 48, 45-052 Opole, Poland; dsiodlak@uni.opole.pl (D.S.); \\ olszowyaleksandraa@gmail.com (A.P.) \\ 2 Department of Chemical Biology and Genetics, Centre of Region Haná for Biotechnological and Agricultural \\ Research, Faculty of Science, Palacký University, Olomouc, Holice CZ-78371, Czech Republic; \\ karel.dolezal@upol.cz \\ 3 Laboratory of Growth Regulators, Faculty of Science, Palacký University \& Institute of Experimental Botany \\ AS CR, Olomouc, Holice CZ-78371, Czech Republic \\ * Correspondence: wsiodlak@uni.opole.pl; Tel.: +48-077-452-7124
}

Received: 10 November 2019; Accepted: 6 December 2019; Published: 8 December 2019

\begin{abstract}
A series of titanium and vanadium complexes with oxazoline 2-(4,5-dihydro-1,3-oxazol2-yl)phenol (L1), 2-(4-methyl-4,5-dihydro-1,3-oxazol-2-yl)phenol (L2), and oxazine 2-(5,6-dihydro$4 H-1,3-o x a z i n-2-y l) p h e n o l$ (L3) ligands were synthesized, and their structures were determined by $\mathrm{NMR}$ and MS methods as $(\mathrm{L})_{2} \mathrm{MtCl}_{2}$. The vanadium complexes were found to be highly active in ethylene $(7300 \mathrm{kgPE} /(\mathrm{molV} \cdot \mathrm{h}))$ and ethylene/norbornene $(5300 \mathrm{kgCop} /(\mathrm{molV} \cdot \mathrm{h}))$ (co)polymerization. The polyethylene characteristics were melting temperature $\left(123-142{ }^{\circ} \mathrm{C}\right)$, crystallinity degree (49-75\%), molecular weight $\left(5.7-8.5 \times 10^{5} \mathrm{~g} / \mathrm{mol}\right)$, molecular weight distribution (1.5-2.4). The ethylene-norbornene (E-NB) copolymer characteristics were molecular weight $\left(2.6-0.9 \times 10^{5} \mathrm{~g} / \mathrm{mol}\right)$, molecular weight distribution (1.6-2.2), glass transition temperature $\left(4-62^{\circ} \mathrm{C}\right)$, norbornene incorporation (12.3-30.1 mol\%) at initial concentration (0.5-1.5 mol/L). The microstructure of E-NB copolymers depends on the catalyst applied with the highest diads content for the $(\mathrm{L} 3)_{2} \mathrm{VCl}_{2}$ and triads for the $(\mathrm{L} 2)_{2} \mathrm{VCl}_{2}$ complexes.
\end{abstract}

Keywords: polyethylene; norbornene copolymers; oxazole ligand; oxazine ligand; vanadium catalyst

\section{Introduction}

Copolymers of ethylene with norbornene (E-NB) of interest for both science and industry. The best known and most widely produced are the E-NB copolymers APEL ${ }^{\mathrm{TM}}$ and TOPAS, which are classified to cyclic olefin copolymers (COCs). The characteristic features of COC materials are high transparency, water and gas impermeability, and low density. Furthermore, high ultraviolet transmission makes these copolymers an alternative to quartz glass. The mechanical properties such as high stiffness, endurance, and hardness and chemical non-reactivity such us resistance for acids and bases, insolubility in polar solvent (e.g., alcohols), together with non-toxicity (lack of estrogenic activity), open the possibility of wide applications, including medical apparatus, the pharmaceutical industry, electrical equipment, and packaging. COCs have been used, among others, as packaging foils (heat shrink wrap and labels, twist-type foils, bubble wraps), lenses, vials, cuvettes and microplates, and blister packaging for medicines. It is also possible to use this type of copolymer as a glass substitute in any apparatus using optical phenomena [1-11]. An important feature of the COC materials is possibility to modify them in wide range of physical parameters. One of the methods to do this is to use a designed catalyst that has a 
direct impact on the molecular structure of copolymer, which in turn affects its properties $[1,6,7,10-16]$. The key factor determining tacticity and distribution of mers in the polymer chain is catalyst symmetry, which depends on the presence of various ligands in the coordination sphere of transition metal [1,6-18]. Similar to the synthesis of polyethylene and ethylene copolymers with 1-olefins, in particular E-NB copolymers, the catalysts with zirconium $[1,6,12,19]$ and titanium $[8,12,20]$ atoms in the active center are the most often studied. The vanadium catalysts [21,22] are less studied, but they receive interest because it is possible to obtain the E-NB copolymers with high molecular weight, narrow molecular weight distribution, and high norbornene incorporation [13,15-18,23-26]. In contrast to the zirconium and titanium catalysts, which work best after methylaluminoxane (MAO) activation $[1,6-8,12,19,20]$, the vanadium catalysts reveal the best performance when activated by $\mathrm{AlEt}_{2} \mathrm{Cl}$ in the presence of reactivator, ethyl trichloroacetate (ETA), which prevents reduction of the vanadium atom to lower oxidation states and influences positively termination and re-initiation processes [13-18]. A method of stabilizing the vanadium active center, and in consequence, a prolongation of catalyst lifetime, is to apply ligands with electron-donating atoms—oxygen, nitrogen, or phosphorus [14-18,20-28].

Heterocyclic compounds like 4,5-dihydro-1,3-oxazole (oxazoline) derivatives seem to meet this requirement. These types of compounds are successfully applied in various reactions, e.g., Diels-Alder, Michael addition, allyl substitution, or epoxidation [29,30]. In our previous work, 2-(1,3-oxazolin-2-yl)pyridine (Py-ox) and 2,6-bis(1,3-oxazolin-2-yl)pyridine (Py-box) ligands were investigated and found to be active in the ethylene polymerization and copolymerization [18]. As a consequence, we decided to return to the idea of Cozzi and co-workers [30,31] and study bicyclic oxazoline ligands, which join phenol moieties where the coordination of the transition metal is through oxygen atom and maintaining five-membered 4,5-dihydro-1,3-oxazole ring with sp2 nitrogen atom (Figure 1). Thus, the proposed catalysts resembles those of the Fujita catalyst [32-34], but they differ with electron density because of the oxygen atom neighboring the $\mathrm{C}=\mathrm{N}$ bond, which should increase its stability through $\pi$-resonance. The following three type of ligands were investigated: 2-(4,5-dihydro-1,3-oxazol-2-yl)phenol (L1) as well as its methylated analogue 2-(4-methyl-4,5-dihydro-1,3-oxazol-2-yl)phenol (L2), which should impose some steric hindrance. Additionally, its seem valuable to study 2-(5,6-dihydro-4H-1,3-oxazin-2-yl)phenol (L3), which is the six-membered analogue and constitution isomer of L2, to compare both the performance of catalysts and the microstructure of polymer products.



Figure 1. The structure of ligands: (L1) 2-(4,5-dihydro-1,3-oxazol-2-yl)phenol, (L2) 2-(4-methyl-4,5dihydro-1,3-oxazol-2-yl)phenol, (L3) 2-(5,6-dihydro-4H-1,3-oxazin-2-yl)phenol.

\section{Results and Discussion}

\subsection{Synthesis and Analysis of the Catalysts}

The synthesis of ligands was modification of the procedure described by Sarada and co-workers [35]. In a three-step procedure, methyl 2-hydroxybenzoate reacts with the appropriate amino alcohol to form the intermediate hydroxybenzamide, which is then converted with $\mathrm{SOCl}_{2}$ to the hydrochloride, which reacts with $\mathrm{NaHCO}_{3}$ to the final product. The synthesis of complexes was based on the work described by Cozzi and co-workers [31], but it was found that dichloromethane acts better as solvent (Figure S1).

The main differences in chemical shifts between the ligands and its titanium and vanadium complexes are depicted in the spectra ${ }^{13} \mathrm{C}$ NMR in DMSO-d6 for the complexes with the ligand L1 (Figure S2). The signals of oxazoline methylene carbons are shifted upfield from $\delta 67$ and $53 \mathrm{ppm}$ in the 
molecule L1 to 44 and $42 \mathrm{ppm}$ in the complexes. In contrast, the signal of the C2 oxazoline carbon and quaternary C2 phenol carbon are shifted downfield from $\delta 165$ and 110 ppm in the molecule L1 to 169 and $116 \mathrm{ppm}$ in the complexes. This indicates electron density changes due to metal atom coordination. Similar tendency is also recorded for the L2 and L3 complexes. Detailed spectra ${ }^{1} \mathrm{H}$ and ${ }^{13} \mathrm{C}$ NMR for the titanium and vanadium complexes with the L1-L3 ligands are given in Figures S3-S20.

Further confirmation of the structure of complexes was performed using mass spectrometry (MS). The mass spectra of vanadium complexes (Figures S21, S25-S27) do not show the molecular peaks, but a characteristic pattern of successive decomposition of the complexes by water is seen. For the vanadium complex with L1 ligand the peaks at $\mathrm{m} / \mathrm{z} 409$ and 390 can be assigned to the fragments $\left[(\mathrm{L} 1)_{2} \mathrm{VCl}_{2}-\mathrm{HCl}\right]$ and $\left[(\mathrm{L} 1)_{2} \mathrm{VCl}_{2}-\mathrm{HCl}-\mathrm{Cl}+\mathrm{O}\right]$. Similarly, for the vanadium complexes with $\mathrm{L} 2$ and $\mathrm{L} 3$ ligands, which differ in the structure by methylene unit, the corresponding peaks at $\mathrm{m} / \mathrm{z} 437$ and 418 can be found. The peaks at $\mathrm{m} / \mathrm{z} 63\left[\mathrm{C}_{5} \mathrm{H}_{3}\right]$ (diagnostic for benzene ring compounds), $91\left[\mathrm{C}_{5} \mathrm{HNO}\right.$ and $\left.\mathrm{C}_{6} \mathrm{H}_{3} \mathrm{O}\right]$, and $119\left[\mathrm{C}_{7} \mathrm{H}_{5} \mathrm{NO}\right]$ together with the peaks at $\mathrm{m} / \mathrm{z} 163$ for $\mathrm{L} 1$ and 177 for L2 and L3 show decomposition of the free ligands (Figures S22-S24) and a pattern similar for acetylic acid derivatives. It should be noted that the ligands L2 and L3 are constitution isomers and have the same molecular mass, but difference in intensity of the peaks at m/z 177 can be seen, which can be explained by greater stability of the six membered oxazine ring.

The mass spectra of titanium complexes (Figures S28, S29-S31) also shows the peaks at m/z 406 $\left[(\mathrm{L} 1)_{2} \mathrm{TiCl}_{2}-\mathrm{HCl}\right]$ and $434\left[(\mathrm{~L} 2)_{2} \mathrm{VCl}_{2}-\mathrm{HCl}\right]$ resulting from loss of chloride atom. However, there is the characteristic peak at $\mathrm{m} / \mathrm{z} 252$, regardless of the titanium complex analyzed, which can be assigned to $\left[(\mathrm{PhO})_{2} \mathrm{TiO}\right]$ fragment resulting from loss of chloride atoms and oxazoline or oxazine fragment of ligands. In summary, the analysis of mass spectra indicates that the studied complexes contain two ligands for metal atom, which is consistent with literature [31,36].

\subsection{Ethylene Polymerization}

The obtained titanium and vanadium complexes were applied as catalyst precursors for ethylene polymerization (Table 1). The polymerization reaction was performed in hexane in the presence of activator, $\mathrm{AlEt}_{2} \mathrm{Cl}$. In the case of the vanadium catalysts, a reactivator ethyl trichloroacetate (ETA) was also used. The titanium complexes, regardless of the type of ligand, show relatively low activities, which do not exceed $140 \mathrm{kgPE} / \mathrm{mol}$ Ti per $1 \mathrm{~h}$. The highest activity was obtained for the catalyst with the ligand L1. The increase of amount of the alkylaluminium activator results in a relatively small increase of polymerization yield. The obtained polyethylene has low melting temperature, in the range of $112-126^{\circ} \mathrm{C}$ and crystallinity degree determined by the differential scanning calorimetry (DSC) method in the range of $48-68 \%$.

Table 1. Results of ethylene polymerization using studied titanium and vanadium catalysts.

\begin{tabular}{|c|c|c|c|c|c|c|}
\hline Item & Catalyst & $\mathrm{Al} / \mathrm{Mt}^{\mathrm{a}}$ & Yield (g) & Activity $^{\text {b }}$ (kg PE/molMt) & $\operatorname{Tm}\left({ }^{\circ} \mathrm{C}\right)$ & $X \operatorname{DSC}(\%)$ \\
\hline 1 & \multirow{2}{*}{$(\mathrm{L} 1)_{2} \mathrm{TiCl}_{2}$} & 1500 & 0.68 & 136 & 118.3 & 48.2 \\
\hline 2 & & 1000 & 0.54 & 108 & 125.8 & 53.3 \\
\hline 3 & \multirow{3}{*}{$(\mathrm{L} 1)_{2} \mathrm{VCl}_{2}$} & 1500 & 5.37 & 1074 & 131.2 & 65.4 \\
\hline 4 & & 1000 & 6.02 & 1204 & 140.2 & 71.2 \\
\hline $5^{c}$ & & 1000 & 18.25 & 7300 & 141.7 & 74.9 \\
\hline 6 & \multirow{2}{*}{$(\mathrm{L} 2)_{2} \mathrm{TiCl}_{2}$} & 1500 & 0.34 & 68 & 111.9 & nd \\
\hline 7 & & 1000 & 0.20 & 40 & 120.8 & 49.0 \\
\hline 8 & \multirow{3}{*}{$(\mathrm{L} 2)_{2} \mathrm{VCl}_{2}$} & 1500 & 2.49 & 498 & 123.5 & 48.9 \\
\hline 9 & & 1000 & 3.30 & 660 & 132.6 & 66.3 \\
\hline $10^{\mathrm{c}, \mathrm{d}}$ & & 1000 & 11.26 & 4504 & 140.0 & 72.5 \\
\hline 11 & \multirow{2}{*}{$(\mathrm{L} 3)_{2} \mathrm{TiCl}_{2}$} & 1500 & 0.42 & 84 & 119.4 & nd \\
\hline 12 & & 1000 & 0.39 & 72 & 122.6 & 68.2 \\
\hline
\end{tabular}


Table 1. Cont.

\begin{tabular}{ccccccc}
\hline Item & Catalyst & $\mathbf{A l} / \mathbf{M t}^{\mathbf{a}}$ & Yield (g) & Activity $\left.^{\mathbf{b}} \mathbf{( k g} \mathbf{P E} / \mathbf{m o l M t}\right)$ & $\mathbf{T m}^{\left({ }^{\circ} \mathbf{C}\right)}$ & $\mathbf{X ~ D S C ~ ( \% )}$ \\
\hline 13 & & 1500 & 3.16 & 632 & 138.2 & 64.8 \\
$14^{\mathrm{c}, \mathrm{d}}$ & & 1500 & 9.24 & 3696 & 132.6 & 58.5 \\
15 & $(\mathrm{~L} 3)_{2} \mathrm{VCl}_{2}$ & 1000 & 4.21 & 842 & 140.6 & 72.0 \\
$16^{\mathrm{c}, \mathrm{d}}$ & & 1000 & 14.45 & 5780 & 135.9 & 71.9 \\
\hline
\end{tabular}

Polymerization conditions: catalyst $\left(5.0 \times 10^{-6} \mathrm{molMt}\right)$, activator $\mathrm{AlEt}_{2} \mathrm{Cl}$, temperature $\left(30^{\circ} \mathrm{C}\right)$, polymerization time (60 min), solvent-hexane $(150 \mathrm{~mL}) .{ }^{\mathrm{a}} \mathrm{Al} / \mathrm{Mt}$ molar ratio. ${ }^{\mathrm{b}}$ Activity in $\mathrm{kg}$ polymer per mol Mt per h. ${ }^{\mathrm{c}}$ Reaction with ethyl trichloroacetate (ETA) $\left(3.5 \times 10^{-4} \mathrm{~mol}\right){ }^{\mathrm{d}}$ Polymerization time $(30 \mathrm{~min})$. nd-Not determined.

The vanadium complexes, also activated by $\mathrm{AlEt}_{2} \mathrm{Cl}$, show almost 10 times higher activities. The highest activity was also obtained using the catalyst with the ligand L1. The increase of alkylaluminium activator, from the molar ratio $\mathrm{Al}: \mathrm{V} 1000$ up to 1500 results in a decrease of polymerization yield, in contrast to the titanium analogues. However, in the presence of ETA reactivator, a further increase of activity was achieved, almost seven times higher. It should be also noticed that the reaction time was shortened from 60 to $30 \mathrm{~min}$ because the reactor was full of the polymer product. The best result $7300 \mathrm{kgPE} /(\mathrm{molV} \cdot \mathrm{h})$ shows the catalyst with the ligand L1, $5800 \mathrm{kgPE} /(\mathrm{molV} \cdot \mathrm{h})$ for the complex L3 and $4500 \mathrm{kgPE} /(\mathrm{molV} \cdot \mathrm{h})$ for the complex L2 (Table 1, items 5, 16 and 10). These differences can be explained by a steric effect, which for the vanadium catalysts often results in changes of activity [21,37-39]. The obtained polyethylene has the melting temperature and crystallinity degree in the range of $123-142{ }^{\circ} \mathrm{C}$ and $49-75 \%$, respectively, and higher values of these parameters were obtained at lower activator/catalyst molar ratio and in the presence of ETA reactivator. The average molecular weight $\left(\mathrm{M}_{\mathrm{W}}\right)$ determined by the GPC method for the polyethylene samples obtained using the vanadium catalysts, $(\mathrm{L} 1-3)_{2} \mathrm{VCl}_{2}$, activated by $\mathrm{AlEt}_{2} \mathrm{Cl}$ and in the presence of ETA has a value $8.5 \times 10^{5} \mathrm{~g} / \mathrm{mol}$ for L1, $5.7 \times 10^{5} \mathrm{~g} / \mathrm{mol}$ for L2, and $7.2 \times 10^{5} \mathrm{~g} / \mathrm{mol}$ for L3. The molecular weight distribution $\left(\mathrm{M}_{\mathrm{w}} / \mathrm{M}_{\mathrm{n}}\right)$ was $1.5,2.4$, and 1.6, respectively.

\subsection{Ethylene-Norbornene Copolymerization}

Due to low activity of the titanium catalysts in the ethylene homopolymerization, the ethylene-norbornene copolymerization was performed only using the vanadium catalysts. The initial norbornene concentration was established as $0.5,1.0$, and $1.5 \mathrm{~mol} / \mathrm{L}$. The polyreactions were carried out in aliphatic solvent, hexane, in the presence of activator $\mathrm{AlEt}_{2} \mathrm{Cl}$ (1000 and 1500 equivalents to the vanadium compound) and ETA (50 equivalents to the vanadium compound) (Table 2). Addition of norbornene in amount of $0.5 \mathrm{~mol} / \mathrm{L}$ to the reaction mixture decreases the catalyst activity, as compared to the ethylene polymerization, regardless of the catalyst applied. The lowest performance revealed the catalyst with the ligand L3 (Table 2, items 1, 4, and 7). The increase of amount of the activator up to $1500 \mathrm{Al} / \mathrm{V}$ molar ratio does not improve the catalyst performance, in contrary, a decrease was observed. 
Table 2. Results of ethylene-norbornene copolymerization using studied vanadium catalysts.

\begin{tabular}{|c|c|c|c|c|c|c|c|c|}
\hline Item & Catalyst & $\mathrm{NB}(\mathrm{mol} / \mathrm{L})$ & Yield (g) & Activity $^{a}$ & $\mathrm{Mw} / 10^{5}(\mathrm{~g} / \mathrm{mol})^{\mathrm{b}}$ & $\mathbf{M w} / \mathbf{M}_{\mathbf{n}}{ }^{\mathbf{b}}$ & $\operatorname{Tg}\left({ }^{\circ} \mathrm{C}\right)$ & $\mathrm{NB}^{\mathrm{c}}(\mathrm{mol} \%)$ \\
\hline 1 & \multirow{3}{*}{$(\mathrm{L} 1)_{2} \mathrm{VCl}_{2}$} & 0.5 & 20.81 & 4162 & 2.6 & 1.6 & 4.0 & 12.3 \\
\hline 2 & & 1.0 & 25.70 & 5140 & 2.0 & 1.8 & 34.2 & 22.1 \\
\hline 3 & & 1.5 & 26.48 & 5296 & 1.8 & 1.9 & 54.0 & 27.5 \\
\hline 4 & \multirow{3}{*}{$(\mathrm{L} 2)_{2} \mathrm{VCl}_{2}$} & 0.5 & 19.10 & 3820 & 1.6 & 1.7 & 12.8 & 17.1 \\
\hline 5 & & 1.0 & 17.22 & 3444 & 1.3 & 1.9 & 27.2 & 20.7 \\
\hline 6 & & 1.5 & 8.10 & 1620 & 0.9 & 2.2 & 52.9 & 27.2 \\
\hline 7 & \multirow{5}{*}{$(\mathrm{L} 3)_{2} \mathrm{VCl}_{2}$} & 0.5 & 17.71 & 3542 & 1.9 & 1.7 & 22.1 & 19.4 \\
\hline $8^{\mathrm{d}}$ & & 0.5 & 13.58 & 2716 & 1.8 & 1.7 & 14.6 & 17.5 \\
\hline 9 & & 1.0 & 23.88 & 4776 & 1.7 & 1.7 & 53.9 & 26.5 \\
\hline $10^{\mathrm{d}}$ & & 1.0 & 19.67 & 3934 & 1.5 & 1.7 & 43.8 & 21.8 \\
\hline 11 & & 1.5 & 20.32 & 4064 & 1.6 & 1.9 & 61.7 & 30.1 \\
\hline
\end{tabular}

(Co)polymerization conditions: catalyst $\left(5.0 \times 10^{-6} \mathrm{~mol}\right)$, activator $\mathrm{AlEt}_{2} \mathrm{Cl}\left(5.0 \times 10^{-3} \mathrm{molAl}\right)$, ethyl trichloroacetate (ETA) $\left(3.5 \times 10^{-4} \mathrm{~mol}\right)$, temperature $\left(30^{\circ} \mathrm{C}\right)$, (co)polymerization time $(60 \mathrm{~min})$, solvent-hexane $(150 \mathrm{~mL}) .{ }^{\text {a }}$ Activity in kg polymer per mol V per h. ${ }^{b}$ Determined by GPC. ${ }^{\mathrm{c}} \mathrm{NB}$ content (mol\%) estimated by ${ }^{13} \mathrm{C}$ NMR spectra. ${ }^{\mathrm{d}}$ Activator $\mathrm{AlEt}_{2} \mathrm{Cl}\left(7.5 \times 10^{-3}\right.$ molAl $)$.

Further increase of the amount of norbornene $(1.0 \mathrm{~mol} / \mathrm{L})$ results in a considerable increase of the copolymerization yield for the catalysts with the ligands L3 and L1. Nevertheless, the total amount of the polymer product obtained using the catalyst with the ligand L3 is smaller as compared to the analogue L1. Again, the increase of amount of the activator up to $1500 \mathrm{Al} / \mathrm{V}$ molar ratio does not help to improve the catalyst performance. Interestingly, a decrease of the activity was observed for the catalyst with the ligand L2 (Table 2, items 2, 5, 9, and 10).

At the highest tested norbornene concentration $(1.5 \mathrm{~mol} / \mathrm{L})$ the increase of activity was observed only for the catalyst with the ligand L1. For those with ligands L2 and L3, the activity decreases, in particular for L2 (Table 2, items 3, 6, and 11). The presented results indicate that the highest copolymerization yield is obtained using the catalyst with the ligand L1, which is sterically least crowded.

Typically, the molecular weight $\left(\mathrm{M}_{\mathrm{W}}\right)$ of the obtained copolymers is considerably lower than that for polyethylene and decreases with increase of the initial norbornene concentration $[12,24,40]$. The studied catalysts produce the copolymer with $\mathrm{M}_{\mathrm{w}}$ in the range of $\left(2.6-0.9 \times 10^{5} \mathrm{~g} / \mathrm{mol}\right)$ and its decrease is observed especially for the catalyst with the ligand L2. The molecular weight distribution $\left(M_{w} / M_{n}=1.6-2.2\right)$ is narrow, regardless of the catalyst studied. Again, the broadest distribution is found for the catalyst with the ligand L2.

The norbornene incorporation is in the range of $12.3-30.1 \mathrm{~mol} \%$ and increases with the increase of initial NB concentration in the reaction medium, as determined by the analysis of the NMR spectra of the copolymers (Figures S32-S40). At the investigated range of initial NB concentration $(0.5-1.5 \mathrm{~mol} / \mathrm{L})$, the highest NB incorporation was found in the copolymer obtained using the catalyst with the ligand L3. The increase of the amount of activator does not improve the NB incorporation. Regardless of the catalyst studied, a linear dependence between the NB incorporation and glass transition temperature $\left(\mathrm{T}_{\mathrm{g}}\right)$ is observed (Figure S41). The obtained values of $\mathrm{T}_{\mathrm{g}}\left(4-62{ }^{\circ} \mathrm{C}\right)$ strictly depend on the amount of NB comonomer. Such a linear dependence indicates that the copolymer has homogeneous composition $[12,24]$. The relatively low $\mathrm{T}_{\mathrm{g}}$ values can be explained a relatively low $\mathrm{NB}$ incorporation [41].

\subsection{Norbornene Incorporation}

The incorporation of the norbornene units in the copolymer chain as well as the copolymer microstructure was determined by the analysis of the spectra ${ }^{13} \mathrm{C}$ NMR (Figure 2 and Figures S32-S40). The characteristic for the norbornene unit signals in the range of 50-43 (C2/C3), 42-36 (C1/C4), c.a. 34-31 (C7) and 31-26 (C5/C6) ppm [6,42] are present. The copolymer microstructure depends on the NB incorporation. When the NB incorporation is below $19 \mathrm{~mol} \%$, the copolymers microstructure is quite similar, regardless of the catalyst applied (Figure 2a and Figures S32, S35 and S38). The signals assigned to isolated (46.4, 40.8, and $32.1 \mathrm{ppm})$ and alternated (47.1, 45.6, 41.4, 41.3, 32.2, 32.1, 30.0, 29.9) 
NB units are observed. It is possible to distinguish isotactic and syndiotactic structures. The increase of comonomer incorporation results in the increase of the intensity of signals assigned to the alternated NB units in relation to the signals assigned to the isolated NB units. When the NB incorporation is above $21 \mathrm{~mol} \%$, the signal from NB diads appears at $30.7 \mathrm{ppm}$ and a difference for the studied catalysts can be seen. The signal at $30.7 \mathrm{ppm}$ is clearly seen for the copolymers obtained using the vanadium complexes with the L1 and especially L3 ligands, whereas is barely seen for the analogue L2. In contrast, for the latter, the signals assigned to triads $(48.2,35.7,35.4,34.1,33.7$, and $33.1 \mathrm{ppm})$ appear (Figure $2 b$ and Figures S33, S36 and S39). This difference is further shown at higher NB incorporation. The vanadium complex with the ligand L2 produces longer micro-blocks, whereas triads are not seen in the polymers obtained with the complexes L1 and L3. However, there is a difference, the microstructure of copolymer obtained using the complex L3 contains much higher amount of NB diads than that obtained using the complex L1 (Figure 2c and Figures S34, S37 and S40).



Figure 2. ${ }^{13} \mathrm{C}$ NMR spectra in o-dichlorobenzene-d4 for ethylene-norbornene copolymers: (a) $12 \mathrm{~mol} \%$ $\mathrm{NB},(\mathrm{L} 1)_{2} \mathrm{VCl}_{2},\left(\right.$ b) $27 \mathrm{~mol} \% \mathrm{NB},(\mathrm{L} 3)_{2} \mathrm{VCl}_{2},\left(\right.$ c) $27 \mathrm{~mol} \% \mathrm{NB},(\mathrm{L} 2)_{2} \mathrm{VCl}_{2}$.

\section{Materials and Methods}

\subsection{Materials}

The substrates for syntheses and the methods of purification of solvents are given in the Supplementary Materials.

\subsection{Ligands Synthesis}

Methyl salicylate $\left(\mathrm{C}_{8} \mathrm{H}_{8} \mathrm{O}_{3}\right)$ was obtained from salicylic acid $\left(\mathrm{C}_{7} \mathrm{H}_{6} \mathrm{O}_{3}\right)$ using the standard Fisher procedure. The crude product was purified by distillation. Yield $85 \%$, b.p. $208-211{ }^{\circ} \mathrm{C}$, refractive index 1.5363 .

Methyl salicylate (10 mmole, $1.521 \mathrm{~g})( \pm)$-2-amino-1-propanol (DL-alaninol) $\left(\mathrm{C}_{3} \mathrm{H}_{9} \mathrm{NO}\right)(20 \mathrm{mmol}$, $1.502 \mathrm{~g}$ ) was mixed in acetonitrile $(10 \mathrm{~mL})$ using a magnetic stirrer at room temperature for 3 days under TLC control. After evaporation of solvent using rotary evaporator the crude product was purified using flash chromatography and eluents $\mathrm{CH}_{2} \mathrm{Cl}_{2}$ : MeOH (9:1 volume) with $1.366 \mathrm{~g}$ yield $(70 \%)$ of 2-hydroxy-N-(1-hydroxy-2-propanyl)benzamide $\left(\mathrm{C}_{10} \mathrm{H}_{13} \mathrm{NO}_{3}\right)$. 
To the benzamide $(7 \mathrm{mmol})$ dissolved in chloroform $(10 \mathrm{~mL})$, mixed by a magnetic stirrer at $0{ }^{\circ} \mathrm{C}$ (water-ice bath), thionyl chloride ( $\left.\mathrm{SOCl}_{2}\right)(2.50 \mathrm{~g}, 1.5 \mathrm{~mL}, 21 \mathrm{mmol}, 3$ equivalents) was added dropwise using a syringe. Then, the reaction mixture was left to obtain room temperature and further mixing was maintained for $24 \mathrm{~h}$. Then, heptane was added to precipitate a white solid. The crude product was washed on a Shott funnel using ethyl acetate and heptane and then dried under nitrogen stream to obtain a white solid 2-(4-methyl-4,5-dihydro-1,3-oxazol-2-yl)phenol hydrochloride salt $\left(\mathrm{C}_{10} \mathrm{H}_{12} \mathrm{ClNO}_{2}\right)$ with $1.333 \mathrm{~g}$ yield $(76 \%)$.

The hydrochloric salt $(1.000 \mathrm{~g}, 4.7 \mathrm{mmol})$ was dissolved in water $(10 \mathrm{~mL})$, and then saturated sodium bicarbonate solution (about $10 \mathrm{~mL}$ ) was added slowly dropwise up to the precipitation of white solid. The solid was washed thoroughly with water and dried, resulting in $0.756 \mathrm{~g}(91 \%)$ of product, 2-(4-methyl-4,5-dihydro-1,3-oxazol-2-yl)phenol $\left(\mathrm{C}_{10} \mathrm{H}_{11} \mathrm{NO}_{2}\right)$.

2-(4-methyl-4,5-dihydro-1,3-oxazol-2-yl)phenol: ${ }^{13} \mathrm{C}$ NMR (400 MHz, DMSO-d6) $\delta 163.7,158.6,133.1$, 127.2, 118.4, 115.9, 109.6, 72.6, 59,7, 20.6. ${ }^{1} \mathrm{H}$ NMR (400 MHz, DMSO-d6) $\delta 12.27(1 \mathrm{H}, \mathrm{s}), 7.63(1 \mathrm{H}, \mathrm{d})$, $7.46(1 \mathrm{H}, \mathrm{t}), 7.00(1 \mathrm{H}, \mathrm{d}), 6.98(1 \mathrm{H}, \mathrm{t}), 4.56(1 \mathrm{H}, \mathrm{t}), 4.48(1 \mathrm{H}, \mathrm{m}), 4.04(1 \mathrm{H}, \mathrm{t}), 1.29(3 \mathrm{H}, \mathrm{d}) . \mathrm{MS}(\mathrm{m} / \mathrm{z}) 177$.

2-(4,5-dihydro-1,3-oxazol-2-yl)phenol: ${ }^{13} \mathrm{C}$ NMR (400 MHz, DMSO-d6) $\delta 165.4,159.1,133.6,127.8$, 118.9, 116.5, 110.2, 67.0, 53.0. ${ }^{1} \mathrm{H}$ NMR $(400 \mathrm{MHz}, \mathrm{DMSO}-\mathrm{d} 6) \delta 12.18(1 \mathrm{H}, \mathrm{s}), 7.63(1 \mathrm{H}, \mathrm{d}), 7.44(1 \mathrm{H}, \mathrm{t})$, $7.00(1 \mathrm{H}, \mathrm{d}), 6.93(1 \mathrm{H}, \mathrm{t}), 4.47(2 \mathrm{H}, \mathrm{t}), 4.07(2 \mathrm{H}, \mathrm{t}) . \mathrm{MS}(\mathrm{m} / \mathrm{z}) 163$. M.p. $38.5-39.9^{\circ} \mathrm{C}$.

2-(5,6-dihydro-4H-1,3-oxazin-2-yl)phenol: ${ }^{13} \mathrm{C}$ NMR (400 MHz, DMSO-d6) 8 161.0, 159.3, 133.0, 126.9, 118.1, 117.3, 114.6, 66.0, 40.9, 21.5. ${ }^{1} \mathrm{H}$ NMR $(400 \mathrm{MHz}$, DMSO-d6) $\delta 12.26(1 \mathrm{H}, \mathrm{s}), 7.61(1 \mathrm{H}, \mathrm{d}), 7.32(1 \mathrm{H}$, t), $6.85(1 \mathrm{H}, \mathrm{d}), 6.81(1 \mathrm{H}, \mathrm{t}), 4.43(2 \mathrm{H}, \mathrm{t}), 3.56(2 \mathrm{H}, \mathrm{t}), 1.98(2 \mathrm{H}, \mathrm{m}) . \mathrm{MS}(\mathrm{m} / \mathrm{z})$ 177. M.p. $76.5-77.5^{\circ} \mathrm{C}$.

\subsection{Catalysts Preparation}

All steps were carried out in inert argon atmosphere. A solution of 2-(4,5-dihydro-1,3oxazol-2-yl)phenol (L1) or 2-(4-methyl-4,5-dihydro-1,3-oxazol-2-yl)phenol (L2) or 2-(5,6-dihydro-4H-1,3oxazin-2-yl)phenol (L3) $(3.0 \mathrm{mmol})$ in $\mathrm{CH}_{2} \mathrm{Cl}_{2}(20 \mathrm{~mL})$ was dropped into a stirred suspension of $\mathrm{NaH}$ (3.3 mmol) in $\mathrm{CH}_{2} \mathrm{Cl}_{2}(30 \mathrm{~mL})$. The reaction mixture was stirred at room temperature for $2 \mathrm{~h}$. To the resulting slightly pink solution of disodium salt, a solution of $\mathrm{TiCl}_{4}\left(1.5 \mathrm{mmol}, 1 \mathrm{M}\right.$ in $\left.\mathrm{CH}_{2} \mathrm{Cl}_{2}\right)$ or $\mathrm{VCl}_{4}(1.5 \mathrm{mmol}, 1 \mathrm{M}$ in hexane) was added dropwise. The obtained orange-red (Ti) or dark blue (V) mixture was stirred overnight at room temperature and then filtered to eliminate $\mathrm{NaCl}$. The filtrate was evaporated under reduced pressure, and the orange-red (Ti) or dark blue (V) precipitate was dried under vacuum.

(L1) ${ }_{2} \mathrm{TiCl}_{2}$ : Yield: $64 \%$. Elemental analysis of $\mathrm{C}_{18} \mathrm{H}_{16} \mathrm{~N}_{2} \mathrm{O}_{4} \mathrm{Cl}_{2} \mathrm{Ti}$ : calculated C $48.79 \%, \mathrm{H} 3.64 \%$, N 6.32\%, experimental: C 47.98\%, H 3.78\%, N 6.95\%. ${ }^{1} \mathrm{H}$ NMR (400 MHz, DMSO-d6) $\delta 7.35(\mathrm{t}, 1 \mathrm{H})$, $7.12(\mathrm{~d}, 1 \mathrm{H}), 6.96(\mathrm{~d}, 1 \mathrm{H}), 6.84(\mathrm{t}, 1 \mathrm{H}), 3.75(\mathrm{t}, 2 \mathrm{H}), 3.61(\mathrm{t}, 2 \mathrm{H}) .{ }^{13} \mathrm{C}$ NMR $(400 \mathrm{MHz}$, DMSO-d6) $\delta$ 169.10, $160.11,134.22,128.78,119.18,118.12,115.85,43.46,41.53$.

(L2) ${ }_{2} \mathrm{TiCl}_{2}$ : Yield: $63 \%$. Elemental analysis of $\mathrm{C}_{20} \mathrm{H}_{20} \mathrm{~N}_{2} \mathrm{O}_{4} \mathrm{Cl}_{2}$ Ti: calculated C $50.98 \%, \mathrm{H} 4,28 \%$, N 5.95\%, experimental: C 50.52\%, H 4.58\%, N 6.31\%. ${ }^{1} \mathrm{H}$ NMR (400 MHz, DMSO-d6) $\delta 7.90(\mathrm{~d}, 1 \mathrm{H})$, $7.61(\mathrm{t}, 1 \mathrm{H}), 7.43(\mathrm{t}, 1 \mathrm{H}), 7.34(\mathrm{t}, 1 \mathrm{H}), 4.61(\mathrm{t}, 1 \mathrm{H}), 4.43(\mathrm{t}, 1 \mathrm{H}), 4.24(\mathrm{~m}, 1 \mathrm{H}), 1.26(\mathrm{~d}, 3 \mathrm{H}) .{ }^{13} \mathrm{C}$ NMR $(400$ MHz, DMSO-d6) $\delta$ 168.50, 160.07, 134.34, 128.83, 119.57, 117.23, 115.88, 48.55, 46.78, 21.19.

( $\left.\mathrm{L}_{3}\right)_{2} \mathrm{TiCl}_{2}$ : Yield: $62 \%$. Elemental analysis of $\mathrm{C}_{20} \mathrm{H}_{20} \mathrm{~N}_{2} \mathrm{O}_{4} \mathrm{Cl}_{2}$ Ti: calculated $\mathrm{C} 50.98 \%, \mathrm{H} 4,28 \%$, N 5.95\%, experimental: C 50.12\%, H 4.38\%, N 6.39\%. ${ }^{1} \mathrm{H}$ NMR (400 MHz, DMSO-d6) $\delta 7.64(\mathrm{~d}, 1 \mathrm{H})$, $7.39(\mathrm{t}, 1 \mathrm{H}), 7.00(\mathrm{~d}, 1 \mathrm{H}), 6.85(\mathrm{t}, 1 \mathrm{H}), 4.51(\mathrm{t}, 2 \mathrm{H}), 3.59(\mathrm{t}, 2 \mathrm{H}), 2.04(\mathrm{~m}, 2 \mathrm{H}) .{ }^{13} \mathrm{C}$ NMR $(400 \mathrm{MHz}$, DMSO-d6) $\delta 161.39,160.58,133.92,127.77,118.61,117.48,113.77,67.10,40.57,20.80$.

(L1) ${ }_{2} \mathrm{VCl}_{2}$ : Yield: $62 \%$. Elemental analysis of $\mathrm{C}_{18} \mathrm{H}_{16} \mathrm{~N}_{2} \mathrm{O}_{4} \mathrm{Cl}_{2} \mathrm{~V}$ : calculated C $48.45 \%, \mathrm{H} 3.61 \%$, N 6.28\%, experimental: C 47.92\%, H 3.81\%, N 6.76\%. ${ }^{1} \mathrm{H}$ NMR (400 MHz, DMSO-d6) $\delta 7.97$ (s, 1H), $7.65(\mathrm{~s}, 1 \mathrm{H}), 7.50(\mathrm{~s}, 1 \mathrm{H}), 6.81(\mathrm{~s}, 1 \mathrm{H}), 4.57(\mathrm{t}, 2 \mathrm{H}), 3.92(\mathrm{t}, 2 \mathrm{H}) .{ }^{13} \mathrm{C}$ NMR $(400 \mathrm{MHz}, \mathrm{DMSO}-\mathrm{d} 6) \delta 169.38$, $160.32,134.47,128.67,119.31,117.83,115.80,43.48,41.40$.

(L2) ${ }_{2} \mathrm{VCl}_{2}$ : Yield: $65 \%$. Elemental analysis of $\mathrm{C}_{20} \mathrm{H}_{20} \mathrm{~N}_{2} \mathrm{O}_{4} \mathrm{Cl}_{2} \mathrm{~V}$ : calculated C $50.65 \%, \mathrm{H} 4.25 \%$, N 5.91\%, experimental: C 50.36\%, H 4.54\%, N 6.32\%. ${ }^{1} \mathrm{H}$ NMR (400 MHz, DMSO-d6) $\delta 7.93$ (d, 1H), 
$7.67(\mathrm{~d}, 1 \mathrm{H}), 7.52(\mathrm{t}, 1 \mathrm{H}), 7.41(\mathrm{t}, 1 \mathrm{H}), 4.70(1 \mathrm{H}), 4.51(1 \mathrm{H}), 4.32(1 \mathrm{H}), 4.21(1 \mathrm{H}), 1.28(3 \mathrm{H}) .{ }^{13} \mathrm{C} \mathrm{NMR}$ (400 MHz, DMSO-d6) $\delta 168.53,160.22,134.36,128.75,119.05,117.80,115.78,48.55,46.56,18.23$.

(L3) ${ }_{2} \mathrm{VCl}_{2}$ : Yield: $60 \%$. Elemental analysis of $\mathrm{C}_{20} \mathrm{H}_{20} \mathrm{~N}_{2} \mathrm{O}_{4} \mathrm{Cl}_{2} \mathrm{~V}$ : calculated C $50.65 \%, \mathrm{H} 4.25 \%$, N 5.91\%, experimental: C 50.52\%, H 4.42\%, N 6.21\%. ${ }^{1} \mathrm{H}$ NMR (400 MHz, DMSO-d6) $\delta 7.60(1 \mathrm{H})$, $7.33(1 \mathrm{H}), 6.84(1 \mathrm{H}), 6.80(1 \mathrm{H}), 4.43(2 \mathrm{H}), 3.54(2 \mathrm{H}), 1.98(2 \mathrm{H}) .{ }^{13} \mathrm{C}$ NMR $(400 \mathrm{MHz}, \mathrm{DMSO}-\mathrm{d} 6) \delta 160.63$, $160.05,133.32,127.18,118.28,117.34,114.34,66.41,40.78,21.27$.

\section{4. (Co)Polymerization Procedure}

The glass reactor $(500 \mathrm{~mL})$ was filled with nitrogen, and hexane $(150 \mathrm{~mL})$, norbornene comonomer $(0.5,1.0$ and $1.50 \mathrm{~mol} / \mathrm{L}), \mathrm{AlEt}_{2} \mathrm{Cl},\left(5.0 \times 10^{-3} \mathrm{~mol} \mathrm{Al}\right.$ or $\left.7.5 \times 10^{-3} \mathrm{~mol} \mathrm{Al}\right)$, optionally ethyl trichloroacetate (ETA) $\left(3.5 \times 10^{-4} \mathrm{~mol}\right)$, titanium $(\mathrm{L} 1)_{2} \mathrm{TiCl}_{2},(\mathrm{~L} 2)_{2} \mathrm{TiCl}_{2},(\mathrm{~L} 3)_{2} \mathrm{TiCl}_{2}$, or vanadium $(\mathrm{L} 1)_{2} \mathrm{VCl}_{2},(\mathrm{~L} 2)_{2} \mathrm{VCl}_{2}$, (L3) ${ }_{2} \mathrm{VCl}_{2}$ catalysts $\left(5.0 \times 10^{-6} \mathrm{~mol} \mathrm{Mt}\right)$ as toluene solution $(3 \mathrm{~mL})$ and ethylene was successively added. Reaction was carried out for 30 or $60 \mathrm{~min}$ at $0.5 \mathrm{MPa}$ pressure of ethylene and $30^{\circ} \mathrm{C}$. The reaction was terminated by closure of ethylene feeding, reduction of pressure to $0.1 \mathrm{MPa}$, and the addition of acidified methanol. The polymer product was filtered, washed by hexane, methanol, and dried at $50{ }^{\circ} \mathrm{C}$ to constant mass. Such prepared samples were used for further analyses. To ensure reproducibility of the results, each (co)polymerization reaction was repeated.

\subsection{Polymer Sample Purification}

Polyethylene obtained was washed thoroughly with methanol and dried at $50{ }^{\circ} \mathrm{C}$ to constant mass. Copolymer E-NB obtained was washed thoroughly with hexane, methanol, and dried at $50^{\circ} \mathrm{C}$ to constant mass.

\subsection{Instruments}

${ }^{13} \mathrm{C}$ NMR and ${ }^{1} \mathrm{H}$ NMR spectra of the ligands and complexes, and ${ }^{13} \mathrm{C}$ NMR spectra of the polymers were recorded on a Bruker Ultrashield spectrometer $(400 \mathrm{MHz})$ in dimethyl sulfoxide-d6 and o-dichlorobenzene- $\mathrm{d} 4$ solvent, respectively. Total norbornene incorporation in polymer was calculated using equation: $\mathrm{NB} \mathrm{mol} \%=\left[1 / 3(2 \mathrm{IC} 7+\mathrm{IC} 1 / \mathrm{C} 4+\mathrm{IC} 2 / \mathrm{C} 3) / \mathrm{ICH}_{2}\right] \times 100 \%$ where $\mathrm{ICH}_{2}, \mathrm{IC} 7, \mathrm{IC} 1 / \mathrm{C} 4, \mathrm{IC} 2 / \mathrm{C} 3$ are total area of the ${ }^{13} \mathrm{C}$ NMR signal at 26-31, 31-34, 36-42, and 43-50 ppm.

EI+ mass spectra were recorded using a Polaris $Q$ (Finnigan, CA, US) mass spectrometer equipped with a Direct Insertion Probe (DIP). The compounds were heated in an ion source with a $40-450{ }^{\circ} \mathrm{C}$ temperature gradient, the mass monitoring interval was 50-1000 amu, and spectra were collected using $1.0 \mathrm{~s}$ cyclical scans, applying $70 \mathrm{eV}$ electron energy. The mass spectrometer was directly coupled to an Xcalibur data system.

The melting temperatures, crystallinity, and glass transition temperatures of the polymers were measured by differential scanning calorimetry DSC 2010 TA instrument calorimeter equipped with an automated sampler. The data were collected with the heat/cool/heat cycle at a heating rate of $10{ }^{\circ} \mathrm{C} / \mathrm{min}$ under a nitrogen atmosphere. The polyethylene crystallinity degree was calculated using the equation: $\mathrm{X}=\left(\Delta \mathrm{H}_{\mathrm{f}} / \Delta \mathrm{H}_{\mathrm{t}, \mathrm{c}}\right) \times 100 \%$, where $\Delta \mathrm{H}_{\mathrm{f}}$ is enthalpy of fusion of the polyethylene sample, $\Delta \mathrm{H}_{\mathrm{t}, \mathrm{c}}$ is enthalpy of fusion of standard $(290 \mathrm{~J} / \mathrm{g})$, and $\mathrm{X}$ is crystallinity degree (\%).

Molecular weight and molecular weight distribution of polymer samples were made on a Polymer Laboratories PL-GPC 220 (Agilent, CA, US) gel permeation chromatography system with refractive index and viscosity detectors. Run conditions were as follows: temperature of $160{ }^{\circ} \mathrm{C}$, 1,2,4-trichlorobenzene (TCB) used as a solvent at a flow rate of $1 \mathrm{~mL} / \mathrm{min}$. The polymers were analyzed on a set of Olexis gel columns. The instrument was calibrated using polyethylene and polystyrene standards with narrow molecular weight distribution.

Elemental analysis (EA) was performed using apparatus EA 1108 Fisons (Shimadzu, JP). 


\section{Conclusions}

The studied catalysts, especially those containing vanadium metal, turned out to be highly active not only in ethylene polymerization but also ethylene-norbornene copolymerization. The highest activity reveals (L1) ${ }_{2} \mathrm{VCl}_{2}$ complex, activated by $\mathrm{AlEt}_{2} \mathrm{Cl}$ and in the presence of ETA, both in ethylene polymerization (7300 $\mathrm{kgPE} /(\mathrm{molV} \cdot \mathrm{h})$ ) and ethylene/norbornene copolymerization (5300 $\mathrm{kgCop} /(\mathrm{molV} \cdot \mathrm{h}))$. The microstructure of E-NB copolymers depends on the catalyst applied with the highest diads contents for the (L3) ${ }_{2} \mathrm{VCl}_{2}$ and higher microblocks for the (L2) ${ }_{2} \mathrm{VCl}_{2}$ complexes. Comparison to the Fujita catalyst studied in very similar reaction conditions (pressure, hexane solvent, $\mathrm{AlEt}_{2} \mathrm{Cl}$ cocatalyst, temperature) [43,44] shows that the presented 2-hydroxyphenyloxazoline catalysts reveal slightly better performance for titanium but are considerably higher for the vanadium atom center. This opens the way for further studies and changes in the structure of ligands that allow us to obtain complexes capable of producing stereoregular polymers with good yield.

Supplementary Materials: The following are available online at http://www.mdpi.com/2073-4344/9/12/1041/s1, Figure S1. Scheme of synthesis.; Figures S2-S20. NMR spectra of L1-L3 ligands and Ti and V complexes, Figures S21-S31. Mass spectra of ligands L1-L3 and complexes Ti and V, Figures S32-S40. ${ }^{13}$ C NMR spectra of ethylene-norbornene copolymers.; Figure S41. Plot of NB incorporated in the copolymers versus the copolymers $\mathrm{T}_{\mathrm{g}}$ using the vanadium complexes.

Author Contributions: Conceptualization, W.O.-S.; Ligand synthesis, D.S. and S.H.; Catalysts synthesis, W.O.-S.; Polymerization, W.O.-S.; Data analysis, W.O.-S., A.P. and D.S.; MS measurement, W.O.-S. and H.O., Writing, W.O.-S. and D.S., Consultation, K.D.

Funding: This work was funded by the Ministry of Education, Youth and Sports of the Czech Republic, an ERDF project entitled "Development of Pre-Applied Research in Nanotechnology and Biotechnology" (No. CZ.02.1.01/0.0/0.0/17_048/0007323).

Acknowledgments: We would like to thank Hana Omamikova for the help during MS measurement and Szymon Herman for help in ligands synthesis.

Conflicts of Interest: The authors declare no conflict of interest.

\section{References}

1. Forsyth, J.F.; Scrivani, T.; Benavente, R.; Marestin, C.; Perena, J.M. Thermal and dynamic mechanical behavior of ethylene/norbornene copolymers with medium norbornene contents. J. Appl. Polym. Sci. 2001, 82, 2159-2165. [CrossRef]

2. Lamonte, R.R.; McNally, D. Cyclic olefin copolymers. Adv. Mater. Process. 2001, 3, 33-36.

3. Nunes, S.P.; Ohlsson, P.D.; Ordeig, O.; Kutter, P.J. Cyclic olefin polymers: Emerging materials for lab-on-a-chip applications. Microfluid. Nanofluid. 2010, 9, 145-161. [CrossRef]

4. Mitsui Chemicals America, INC. Available online: www.mitsuichemicals.com (accessed on 7 December 2019).

5. TOPAS Advanced Polymers. Available online: www.topas.com/products-topas_coc (accessed on 7 December 2019).

6. Tritto, I.; Boggioni, L.; Ferro, D.R. Metallocene catalyzed ethene- and propene co-norbornene polymerization: Mechanisms from a detailed microstructural analysis. Coord. Chem. Rev. 2006, 250, 212-241. [CrossRef]

7. Blank, F.; Janiak, C. Metal catalysts for the vinyl/addition polymerization of norbornene. Coord. Chem. Rev. 2009, 253, 827-861. [CrossRef]

8. Pei, L.; He, S.; Gao, J.; Liao, H.; Gao, H. Homo- and copolymerizations of ethylene and norbornene using bis( $\beta$-ketoamino) titanium catalysts containing pyrazolone rings. Polymers 2017, 9, 262. [CrossRef] [PubMed]

9. Huo, P.; Liu, W.; He, X.; Wang, H.; Chen, Y. Nickel(II) complexes with three-dimensional geometry $\alpha$-diimine ligands: Synthesis and catalytic activity toward copolymerization of norbornene. Organometallics 2013, 32, 2291-2298. [CrossRef]

10. Manteghi, A.; Arabi, H.; Jahani, Y. Synthesis, characterization, rheological and thermal behavior of metallocene ethylene-norbornene copolymers with low norbornene content using pentafluorophenol modified methylaluminoxane. Polym. Int. 2015, 64, 900-906. [CrossRef] 
11. He, X.; Deng, Y.; Jiang, X.; Wang, Z.; Yang, Y.; Han, Z.; Chen, D. Copolymerization of norbornene and butyl methacrylate at elevated temperatures by a single centre nickel catalyst bearing bulky bis ( $\alpha$-diimine) ligand with strong electron-with drawing groups. Polym. Chem. 2017, 8, 2390-2396. [CrossRef]

12. Zhao, W.; Nomura, K. Design of efficient molecular catalysts for synthesis of cyclic olefin copolymers (COC) by copolymerization of ethylene and $\alpha$-olefins with norbornene or tetracyclododecene. Catalysts 2016, 6, 175. [CrossRef]

13. Leone, G.; Pierro, I.; Zanchin, G.; Forni, A.; Bertini, F.; Rapallo, A.; Ricci, G. Vanadium(III)—Catalyzed copolymerization of ethylene with norbornene: Microstructure at tetrad level and reactivity ratios. J. Mol. Catal. A Chem. 2016, 424, 220-231. [CrossRef]

14. Zanchin, G.; Gavezzoliy, A.; Bertini, F.; Ricci, G.; Leone, G. Homo- and Copolymerization of Ethylene with Norbornene Catalyzed by Vanadium(III) Phosphine Complexes. Molecules 2019, 24, 2088. [CrossRef] [PubMed]

15. Zanchin, G.; Vendier, L.; Pierro, I.; Bertini, F.; Ricci, G.; Lorber, C.; Leone, G. Homo- and co-polymerization of ethylene with cyclic olefins catalyzed by phosphine adducts of (imido)vanadium(IV) complexes. Organometallics 2018, 37, 3181-3195. [CrossRef]

16. Zanchin, G.; Pierro, I.; Parisini, E.; Martí-Rujas, J.; Ricci, G.; Leone, G. Synthesis, structure and behavior of vanadium(III) diphosphine complexes in the homo- and co-polymerization of ethylene with norbornene: The ligand donor strength and bite angle make the difference. J. Organomet. Chem. 2018, 861, 142-150. [CrossRef]

17. Yan, Q.; Sun, Z.L.; Zhang, W.J.; Nomura, K.; Sun, W.H. Vanadyl Di (5-t-butyl-2-(aryliminomethyl)quinolin8-olate): Synthesis, Characterization, and Ethylene (Co-)Polymerization. Macromol. Chem. Phys. 2014, 215, 1744-1752. [CrossRef]

18. Ochędzan-Siodlak, W.; Bihun-Kisiel, A.; Siodlak, D.; Poliwoda, A.; Dziuk, B. Titanium and vanadium catalysts with oxazoline ligands for ethylene-norbornene (co)polymerization. Eur. Polym. J. 2018, 106, 148-155. [CrossRef]

19. Boggioni, L.; Sidari, D.; Losio, S.; Stehling, U.M.; Auriemma, F.; Malafronte, A.; Girolamo, R.D.; Rosa, C.D.; Tritto, I. Ethylene-co-norbornene copolymerization using a dual catalyst system in the presence of a chain transfer agent. Polymers 2019, 11, 554. [CrossRef]

20. Wang, H.; Cheng, H.; Tanaka, R.; Shiono, T.; Cai, Z. Efficient control of ethylene-norbornene copolymerization behavior of a fluorenylamido-ligated titanium complex: Substituent effects of the amido ligand and copolymer properties. Polym. Chem. 2018, 9, 4492-4497. [CrossRef]

21. Wu, J.Q.; Li, Y.S. Well-defined vanadium complexes as the catalysts for olefin polymerization. Coord. Chem. Rev. 2011, 255, 2303-2314. [CrossRef]

22. Langeslay, R.R.; Kaphan, D.M.; Marshall, C.L.; Stair, P.C.; Sattelberger, A.P.; Delferro, M. Catalytic applications of vanadium: A mechanistic perspective. Chem. Rev. 2019, 119, 2128-2191. [CrossRef]

23. Budagumpi, S.; Keri, R.S.; Biffis, A.; Patil, S.A. Olefin poly/oligomerizations by metal precatalysts bearing non-heterocyclic N-donor ligands. Appl. Catal. A Gen. 2017, 535, 32-60. [CrossRef]

24. Diteepeng, N.; Tang, X.; Hou, X.; Li, Y.S.; Phomphrai, K.; Nomura, K. Ethylene polymerisation and ethylene/norbornene copolymerisation by using aryloxo-modified vanadium $(\mathrm{V})$ complexes containing 2,6-difluoro-, dichloro-phenylimido complexes. Dalton Trans. 2015, 44, 12273-12281. [CrossRef] [PubMed]

25. Liu, Y.; Xiang, H.X.; Wang, K.T.; Wu, G.; Li, Y.B. Efficient preparation of cyclic olefin copolymers with unreacted double bonds by using thermal stable non-metallocene vanadium catalytic system. Macromol. Chem. Phys. 2019, 220, 1900008-1900017. [CrossRef]

26. Wang, W.; Nomura, K. Notable effects of aluminum alkyls and solvents for highly efficient ethylene (co)polymerizations catalyzed by (arylimido)-(aryloxo)vanadium complexes. Adv. Synth. Catal. 2006, 348, 743-750. [CrossRef]

27. Wu, J.Q.; Mu, J.S.; Zhang, S.W.; Li, Y.S. Vanadium(V) complexes containing tetradentate amine trihydroxy ligands as catalysts for copolymerization of cyclic olefins. J. Polym. Sci. A Polym. Chem. 2010, 48, 1122-1132. [CrossRef]

28. Desimoni, G.; Faita, G.; Jorgensen, K.A. C2-Symmetric chiral bis (oxazoline) ligands in asymmetric catalysis. Chem. Rev. 2006, 106, 3561-3651. [CrossRef]

29. Yang, G.; Zhang, W. Renaissance of pyridine-oxazolines as chiral ligands for asymmetric catalysis. Chem. Soc. Rev. 2018, 47, 1783-1810. [CrossRef] 
30. Cozzi, P.G.; Gallo, E.; Floriani, C.; Chiesi-Villa, A.; Rizzoli, C. (Hydroxyphenyl) oxazoline: A novel and remarkably facile entry into the area of chiral cationic alkylzirconium complexes which serve as polymerization catalysts. Organometallics 1995, 14, 4994-4996. [CrossRef]

31. Cozzi, P.G.; Floriani, C.; Chiesi-Villa, A.; Rizzoli, C. Oxazoline early transition metal complexes: Functionalizable achiral titanium(IV), titanium(III), zirconium(IV), vanadium(III), and chiral zirconium(IV) bis(oxazoline) complexes. Inorg. Chem. 1995, 34, 2921-2930. [CrossRef]

32. Makio, H.; Terao, H.; Iwashita, A.; Fujita, T. FI catalysts for olefin polymerization-a comprehensive treatment. Chem. Rev. 2011, 111, 2363-2449. [CrossRef]

33. Ishii, S.; Nakano, T.; Kawamura, K.; Kinoshita, S.; Ichikawa, S.; Fujita, T. Development of new selective ethylene trimerization catalysts based on highly active ethylene polymerization catalysts. Catal. Today 2018, 303, 263-270. [CrossRef]

34. Long, Y.Y.; Wang, Y.X.; Li, B.X.; Li, Y.G.; Li, Y.S. Quasi-living copolymerization of ethylene with 1-hexene by heteroligated (salicylaldiminato $\beta$-enaminoketonato) titanium complexes. J. Polym. Sci. A Polym. Chem. 2017, 55, 2787-2797. [CrossRef]

35. Sarada, G.; Sim, B.; Cho, W.; Yoon, J.; Gal, Y.S.; Kim, J.J.; Jin, S.H. New sky-blue and bluishegreen emitting $\mathrm{Ir}(\mathrm{III})$ complexes containing an azoline ancillary ligand for highly efficient PhOLEDs. Dye. Pigment. 2016, 131, 60-68. [CrossRef]

36. Traar, P.; Schachner, J.A.; Stanje, B.; Belaj, F.; Mösch-Zanetti, N.C. Dioxomolybdenum(VI) complexes with naphtholate-oxazoline ligands in catalytic epoxidation of olefins. J. Mol. Catal. A Chem. 2014, 385, 54-60. [CrossRef]

37. Elagab, H.A.; Alt, H.G. Structure-property-relationship studies with ethylene polymerization catalysts of Ti, $\mathrm{Zr}$ and $\mathrm{V}$ containing heterocyclic ligands. Inorg. Chim. Acta 2015, 437, 26-35. [CrossRef]

38. Wang, F.Z.; Tian, S.S.; Li, R.P.; Li, W.M.; Chen, C.L. Ligand steric effects on naphthyl- $\alpha$-diimine nickel catalyzed $\alpha$-olefin polymerization. Chin. J. Polym. Sci. 2018, 36, 157-162, (English Edition). [CrossRef]

39. Dai, S.; Zhou, S.; Zhang, W.; Chen, C. Systematic investigations of ligand steric effects on $\alpha$-diimine palladium catalyzed olefin polymerization and copolymerization. Macromolecules 2016, 49, 8855-8862. [CrossRef]

40. Nomura, K.; Bahuleyan, B.K.; Zhang, S.; Sharma, P.M.V.; Katao, S.; Igarashi, A.; Inagaki, A.; Tamm, M. Synthesis and structural analysis of (imido)vanadium(V) dichloride complexes containing imidazolin-2-iminato- and imidazolidin-2-iminato ligands, and their use as catalyst precursors for ethylene (co)polymerization. Inorg. Chem. 2014, 53, 607-623. [CrossRef]

41. Forsyth, J.; Perena, J.M.; Benavente, R.; Perez, E.; Tritto, I.; Boggioni, L.; Brintzinger, H.H. Influence of the polymer microstructure on the thermal properties of cycloolefin copolymers with high norbornene contents. Macromol. Chem. Phys. 2001, 202, 614-620. [CrossRef]

42. Boggioni, L.; Losio, S.; Tritto, I. Microstructure of copolymers of norbornene based on assignments of $13 \mathrm{C}$ NMR spectra: Evolution of a methodology. Polymers 2018, 10, 647. [CrossRef]

43. Krasuska, A.; Białek, M.; Czaja, K. Ethylene polymerization with FI complexes having novel phenoxy-imine ligands: Effect of metal type and complex immobilization. J. Polym. Sci. A Polym. Chem. 2011, 49, 1644-1654. [CrossRef]

44. Białek, M.; Bisz, E. Polypropylene and poly (ethylene-co-1-octene) effective synthesis with diamine-bis (phenolate) complexes: Effect of complex structure on catalyst activity and product microstructure. Polym. Sci. A Polym. Chem. 1017, 55, 2467-2476. [CrossRef]

(C) 2019 by the authors. Licensee MDPI, Basel, Switzerland. This article is an open access article distributed under the terms and conditions of the Creative Commons Attribution (CC BY) license (http://creativecommons.org/licenses/by/4.0/). 